\title{
Effect of Time in the Development of Perforated Appendicitis
}

\author{
Kemal Atahan, ${ }^{\mathrm{a}, \mathrm{b}}$, Enis Aslan ${ }^{\mathrm{a}}$, Orhan Üreyen ${ }^{\mathrm{a}}$, Atilla Çökmez ${ }^{\mathrm{a}}$, Ercüment Tarcan ${ }^{\mathrm{a}}$
}

\begin{abstract}
Background: The aim of this study was to elucidate the natural history of appendicitis with respect to prehospital duration of pain before operation.
\end{abstract}

Methods: We retrospectively evaluated 363 patients who were operated with a pre-diagnosis of acute appendicitis at our hospital. The patients were divided into three groups as acute, phlegmonous, and perforated according to histological and clinical findings. Preoperative white blood cell counts (WBC) and ultrasound reports, age, gender, time before attendence and postoperative hospital stay were recorded.

Results: The mean time of pain duration before operation for perforated appendicitis was not significantly longer for patients $>50$ years of age compared to younger age groups with perforation. Postoperative complications found higher in group 3. Analysis stratified by age and gender, the total duration of pain before operation was not statistically significant. WBC count and postoperative stay in hospital of Group 3 was significantly higher. Concordance between ultrasound and pathology was not statistically significant.

Conclusions: Patient delay in presentation is the predominant factor determining the incidence of complicated appendicitis, and this delay is not influenced by age or gender. Negative appendectomy rates were higher in females who were in reproductive ages. Ultra-

Manuscript accepted for publication December 28, 2011

${ }^{a}$ Ataturk Educational and Research Hospital 1st Surgical Department, Izmir, Turkey

${ }^{\mathrm{b}}$ Corresponding author: Kemal Atahan, 6342 sok. No: 44 Ayse Kaya 2 apt. Kat: 3 Daire: 6 35540, Bostanlı Izmir, Turkey.

Email: kemalatahan@yahoo.com.tr

doi: $10.4021 / \mathrm{jcs} 18 \mathrm{e}$ sound did not improve the diagnostic accuracy when compared to the clinical assessment.

Keywords: Acute abdominal pain; Acute appendicitis; Diagnosis

\section{Introduction}

Acute appendicitis is one of the most common surgical diseases, but diagnostic problems are common, even for experienced surgeons. In the clinical presentation of appendicitis, there are various symptoms and signs with almost infinite variations [1]. At least $20 \%$ to $30 \%$ of the patients have atypical symptoms, signs or laboratory findings. Although physician-related diagnostic delays have been reported [1, 2], patient-related factors constitute the main reason of delays [3-5]. It is assumed that there has been a close relation between the level of inflammation or perforation and duration of inflammation [6], however, this idea has been declined with an argument among two main appendicitis types with and without tendency to perforation $[7,8]$. There have been lack of data on the progress of appendicitis in time [3,9] and it is unclear whether the risk of appendix perforation is mainly related to the duration of inflammation or it is because of the patient related factors. It is suggested that acute appendicitis is more aggressive disease in the elderly, presenting a more rapid progression towards perforation [10]. The objective of this study is to identify the natural history of appendicitis, based on the pre-operative duration of pain.

\section{Materials and Methods}

This study was retrospectively conducted in patients who were hospitalized with acute appendicitis pre-diagnosis in Izmir Ataturk Training and Research Hospital, 1st General Surgery clinic between January-2006 and December 2009 and who underwent to appendectomy surgery. During the study period, 372 patients with acute appendicitis were operated, 363 of those, who could remember the onset of abdominal pain, were included in the study. Patients, under the 
Table 1. Demographic Characteristics of the Patients

\begin{tabular}{llll}
\hline Age Group & Male (\%) & Female (\%) & All patients (\%) \\
\hline $13-19$ & $51(63.0)$ & $30(37.0)$ & $81(100.0)$ \\
$20-49$ & $143(58.1)$ & $103(41.9)$ & $246(100.0)$ \\
$\geq 50$ & $24(66.7)$ & $12(33.3)$ & $36(100.0)$ \\
\hline Total & $218(60.1)$ & $145(39.9)$ & $363(100.0)$ \\
\hline
\end{tabular}

age of 14 years were excluded. Diagnosis was made by the surgeon, who was on duty in the emergency surgery clinic, on the basis of the patient's history and clinical findings. All appendectomy operations were performed as open surgeries. All appendectomy samples were histologically evaluated by the same pathologist in the hospital. All female patients were pre-operatively evaluated by obstetrics and gynecology physicians and patients were operated in the case that other operative pathologies were not detected as a result of these consultations.

Patients were separated into 3 groups according to their histological and clinical symptoms:

Group 1: Patients with macroscopically identified acute appendicitis, who pathologically demonstrated polymorphonuclear infiltration in the appendix wall, and patients with chronic appendicitis and reactive lymphoid hyperplasia without any pathological finding.

Group 2: Patients with macroscopically detected partial or complete phlegmonous appendicitis and pathologically detected intact appendix mucosa, moderate inflammatory cell infiltrant or partial necrosis.

Group 3: Patients with macroscopically or histologically-detected perforated acute appendicitis or cell infiltrant with perforated appendix mucosa or a strong panmural inflammatory appendix in correspondence with an accompanying inflamed appendix.

During the course of the study, there were 45 negative appendectomy cases (19 male and 26 female) and all of them were excluded. The final diagnosis of these cases were as follows: Non-specific abdominal pain $(\mathrm{n}=12)$, lymphadenitis mezentherica $(n=3)$, Meckel's diverticulitis $(n=2)$, gastroenteritis $(n=2)$, cholecystitis $(n=2)$, uroteric calculus $(n=1)$, primary peritonitis $(n=1), \operatorname{FMF}(n=1)$, carcinoid tumor $(n=1)$, gastroenteritis $(n=1)$, urinary tract infection $(\mathrm{n}=3)$, Miliary tuberculosis $(\mathrm{n}=1)$, Crohn's disease $(\mathrm{n}=1)$, Pelvic inflammatory disease $(n=4)$, ovarian cyst rupture $(n$ $=8)$, ruptured ectopic pregnancy $(\mathrm{n}=1)$, endometriosis $(\mathrm{n}$ $=1)$.

Preoperative white blood cell count (WBC), hemoglobin (HB) and the ultrasonography (USG) results were analyzed for characteristics of the diagnosis. Age, gender, duration of symptoms before admission, duration of hospitalization, length and width of appendix were recorded. The collected data were recorded in an electronic database (Microsoft Excel for Windows), mean values and standard deviations (SD) of numerical factors were calculated and the data were analyzed.

SPSS16.0 program was used for the statistical calculations. Kolmogrov-Smirnov test was performed in order to measure compliance of data distribution. According to this test, there was sufficient number of cases in each group complied with normal distribution. However, as some of the groups were non-complied to normal distribution and with less variable size, Mann Whitney U test was applied for continuous variables. Chi-Square analysis was performed in order to test the rates between the groups. Age of the patients and duration of the symptoms were considered as a risk factor for perforation. Each risk factor was tested by using the

Table 2. Demographic Characteristics of the Patients

\begin{tabular}{lllll}
\hline \multirow{2}{*}{ Group } & $\mathbf{n}$ & \multicolumn{1}{c}{ Age (years) } & \multicolumn{2}{c}{ Gender (n\%) } \\
\cline { 3 - 5 } & & Mean ( $\mathbf{n}$ SD, min-max) & Male & Female \\
\hline 1 & 132 & $30.29 \pm 12.80$ & $64 / 48.4$ & $68 / 51.6$ \\
2 & 186 & $29.31 \pm 12.85$ & $123 / 66.1$ & $63 / 33.9$ \\
3 & 45 & $31.89 \pm 17.20$ & $31 / 68.8$ & $14 / 31.2$ \\
\hline Total & 363 & 29.99 & $218 / 60.1$ & $145 / 39.9$ \\
\hline
\end{tabular}


Table 3. Distribution of Age Gender Stratified Mean Duration of Pre-admission Symptom According to Level of Inflammation

\begin{tabular}{|c|c|c|c|c|c|c|}
\hline \multirow[t]{2}{*}{ Age } & \multicolumn{2}{|c|}{ Acute } & \multicolumn{2}{|c|}{ Phlegmonous } & \multicolumn{2}{|c|}{ Perforated } \\
\hline & $\begin{array}{l}\text { Male(n) } \\
\text { Hour (n) }\end{array}$ & $\begin{array}{l}\text { Female (n) } \\
\text { Hour (n) }\end{array}$ & $\begin{array}{l}\text { Male(n) } \\
\text { Hour (n) }\end{array}$ & $\begin{array}{l}\text { Female (n) } \\
\text { Hour (n) }\end{array}$ & $\begin{array}{l}\text { Male(n) } \\
\text { Hour (n) }\end{array}$ & $\begin{array}{l}\text { Female (n) } \\
\text { Hour (n) }\end{array}$ \\
\hline $13-19$ & $32.0(12)$ & $35.2(15)$ & $34.4(30)$ & $30.0(12)$ & $74.6(9)$ & $160.0(3)$ \\
\hline $20-49$ & $32.8(46)$ & $39.5(48)$ & $37.3(79)$ & $32.6(47)$ & $46.6(18)$ & $87.0(8)$ \\
\hline$\geq 50$ & $36.0(6)$ & $33.6(5)$ & $42.8(14)$ & $66.0(4)$ & $60.0(4)$ & $56.0(3)$ \\
\hline All & $33.0(64)$ & $38.1(68)$ & $37.2(123)$ & $34.2(63)$ & $56.5(31)$ & $96.0(14)$ \\
\hline
\end{tabular}

univariate logistic regression analysis. The relationship between these variables $\mathrm{n}$ the multivariate logistic regression analysis was evaluated. For the age group, there was no significant difference in the gender distribution $(\mathrm{P}=0.516$ and $\mathrm{P}>0.05)$. Therefore, gender was not tested as a factor in the multivariate analysis.

\section{Results}

Totally 363 patients, 145 women and 218 men, were included in our study. The mean age of the patients was 29.99 (median 26, range: 14 - 79). The mean ages of the cases were calcu- lated as $30.29 \pm 12.80$ in Group 1, as $29.31 \pm 12.85$ in Group 2 and as $31.89 \pm 17.20$ in Group 3. At the time of surgery, $23.9 \%(\mathrm{n}=52)$ of males were in Group $1,55.5 \%(\mathrm{n}=121)$ of males were in Group 2 and 20.6\% $(n=45)$ of males were in Group 3. These rates were $42 \%(n=61), 42 \%(n=61)$ and $16 \%(\mathrm{n}=23)$ respectively for females. The number of perforated cases were higher in males compared with females and the difference was found to be statistically significant $(\mathrm{P}$ $=0.008$ and $\mathrm{P}<0.05)$. At the time of pathology, 29.4\% $(\mathrm{n}=$ 64) of males were in Group 1, 56.4\% $(n=123)$ of males were in Group 2 and 14.2\% $(\mathrm{n}=31)$ of males were in Group 3. These rates were $46.9 \%(n=68), 43.4 \%(n=63)$ and $9.7 \%(n$ $=14$ ) respectively for females. The number of phlegmonous

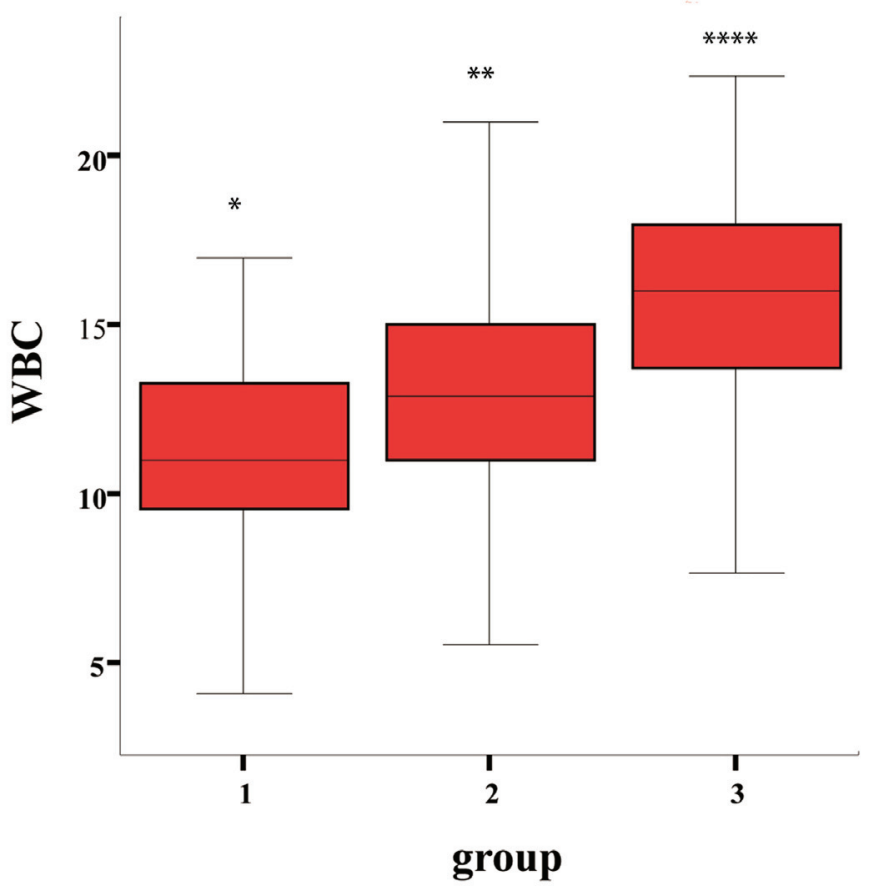

Figure 1. WBC levels in Groups (Groups 1 to 3). 
Table 4. WBC, Bilirubine, Distribution of Average Length and Dimension of Appendix

\begin{tabular}{|c|c|c|c|c|}
\hline Group & $\begin{array}{l}\text { WBC }( \pm \text { SD }) \\
P<0.05\end{array}$ & $\begin{array}{l}\text { HGB }( \pm \text { SD , min-max }) \\
P>0.05\end{array}$ & $\begin{array}{l}\text { Length of appendix } \\
( \pm \mathrm{SD} \text {, min-max }) \\
\mathrm{P}>\mathbf{0 . 0 5}\end{array}$ & $\begin{array}{l}\text { Dimension of appendix } \\
( \pm \mathrm{SD}, \text { min-max }) \\
\mathbf{P}<\mathbf{0 . 0 5}\end{array}$ \\
\hline $\begin{array}{l}1 \\
(n=132)\end{array}$ & $11.54( \pm 3.28)$ & $13.24( \pm 1.7)$ & $6.82( \pm 1.59)$ & $0.82( \pm 0.42)$ \\
\hline $\begin{array}{l}2 \\
(n=186)\end{array}$ & $12.37( \pm 3.24)$ & $13.38( \pm 1.8)$ & $6.91( \pm 1.62)$ & $1.04( \pm 0.68)$ \\
\hline $\begin{array}{l}3 \\
(n=45)\end{array}$ & $15.49( \pm 3.75)$ & $13.34( \pm 1.5)$ & $6.92( \pm 1.53)$ & $1.42( \pm 0.67)$ \\
\hline
\end{tabular}

and perforated cases were higher in males compared with females and the difference was found to be statistically significant $(\mathrm{P}=0.033$ and $\mathrm{P}<0.05)$. Demographic characteristics of patients are shown in Table 1 and Table 2.

Duration of symptoms in patients with perforated appendicitis was significantly longer $(68.80 \pm 12.40$ hours and $\mathrm{P}=0.000, \mathrm{P}<0.001)$. This was found to be statistically significant for both males $(\mathrm{P}=0.004)$ and females $(\mathrm{P}=0.001)$. No difference was found between patients over and under the age of 50, in the basis of the duration of pain during the pre-operation period $(\mathrm{P}=0.584$ and $\mathrm{P}>0.05)$. In the analysis of stratums in perforated patients, based on the age and sex, duration of pre-operative symptoms was very long in females, compared with males. However, this is not statistically significant $(\mathrm{P}=0.486$ and $\mathrm{P}>0.05)$ (Table 3$)$.

In the comparison of WBC levels of the groups, high levels of WBC levels in patients with appendix perforation were statistically significant $(\mathrm{P}<0.05)$ (Fig. 1).

No significant difference was found between the groups in the basis of appendix size and $\mathrm{Hb}$ levels $(\mathrm{P}>0.05)$. Considering the appendix width, the difference between 3 groups was statistically significant $(\mathrm{P}<0.05)$. Appendix width in group 3 was larger than the other groups (Table 4).

It was statistically significant that time of hospitalization was increasing in accordance with the increasing degree of inflammation (Table 5).

Comparison of the pre-operative USGs did not reveal a statistically significant difference between the rates of consistency of USG with pathology $(\mathrm{P}>0.05)$. However, the highest rate of consistency between USG and pathology was identified in perforated group (Table 6).

Mortality was not observed in any of the included patients. Rates of morbidities were found as 3.5\% in total of Group 1 and Group 2 and 26.6\% in Group 3. In Group 1, one patient experienced post-operative sub-ileus and one patient experienced pneumonia. In Group 2, 2 patients experienced post-operative sub-ileus, 2 patients experienced pneumonia and 5 patients experience post-operative scar infection. In Group 3, 3 patients experienced post-operative sub-ileus, 1 patient experienced pneumonia, 1 patient experienced periapendicular abscess and 7 patients experienced scar infection.

Table 5. Distribution of Mean Duration of Hospitalization According to the Level of Inflammation

\begin{tabular}{lll}
\hline & Average \pm SD & P \\
\hline Inflammation & & $0.000^{*}$ \\
Acute & $1.85 \pm 1.03$ & \\
Plegmonous & $2.25 \pm 2.44$ & \\
Perforated or gangrenous & $4.24 \pm 2.39$ \\
\hline
\end{tabular}


Table 6. Distribution of Pathology and USG

\begin{tabular}{lllll}
\hline & $\begin{array}{l}\text { Acute } \\
\mathbf{n}(\mathbf{\%})\end{array}$ & $\begin{array}{l}\text { Phlegmonous } \\
\mathbf{n}(\mathbf{\%})\end{array}$ & $\begin{array}{l}\text { Perforated } \\
\mathbf{n}(\%)\end{array}$ & P \\
\hline USG & & & $25(57.8)$ & \\
Appendicitis (+) & $59(44.7)$ & $87(46.8)$ & $19(42.2)$ & \\
Appendicitis (-) & $73(55.3)$ & $99(53.2)$ & & \\
\hline
\end{tabular}

\section{Discussion}

The major finding of this study is that the time between the onset of symptoms and admission was significantly longer in patients with appendix perforation comparing with the patients with lower inflammation level. Appendix perforation increases the risk of complications up to $39 \%$ and if there is no perforation during the operation, this rate is about $8 \%$ $[11,12]$. Also in our study, complication rates were $26.6 \%$ and $3.7 \%$ in the groups with and without perforation, respectively. Furthermore, in patients with perforated appendix, duration of post-operative hospitalization was significantly higher compared with the other groups.

There have been continuous arguments whether the delays of diagnosis are due to patient-related or physicianrelated factors. Our findings were consistent with the results of previous study, which showed that, appendix perforation mostly depended on the duration of the pre-admission [3, $5,9,13]$. However, some authors have been emphasizing the importance of physician-related delay of diagnosis, as a cause of advanced appendicitis [2]. In our study, 2 of 11 patients, who were not operated up to 24 hours after the admission, were in perforation group. These two patients with performed appendix were hospitalized during total of 12 days after the operation and scar infection developed in one of those. This is reflecting the diagnostic difficulties and repetitive examination policy for non-certain cases. As a result, it may be possible to avoid perforation by an earlier operation. In contrast to a study, which was representing these kinds of delays in elderly [14], delayed cases were in $20-49$ years aged group in our study.

One of the limitations of this study was the exclusion of patients under the age of 13 years old, as they could not be operated due to the absence of pediatric surgeon in the study center.

Diagnostic difficulties are well known for the women in childbearing potential and they generally have uterine or adnexial disease originated symptoms, which could not be differentiated from appendicitis. In our study, 22 of 26 female cases who underwent to negative appendectomy, were the women in childbearing potential.

There have been attempts to confirm the diagnosis with ultrasound and computed tomography (CT). There are several studies, confirming the use of these diagnostic devices $[15,16]$. In the evaluation of USGs in our study, the rate of consistency between method and pathology was highest in the perforated group. However, this difference was not statistically significant. This represents that the importance of USG is the second compared with the clinical examination.

In a prospective, randomized study comparing clinical examination and CT for the diagnosis of acute appendicitis, CT did not increase the accuracy of the diagnosis [17]. CT was not used in our study. According to our data, developed diagnostic methods could only prevent a limited number of perforations, because most of these perforations occured before the admission. Nonetheless, clinical judgment was considered as the most important diagnostic method.

Considering the duration of inflammation, age was not found to cause a pre-admission delay. In our study, there was not a statistically significant difference in the mean duration of pain in the pre-operation period, comparing the patients under and over 50 years old. The duration of symptoms in patients with perforation was relatively long in females, compared with the males. However, this was not statistically significant. Nonetheless, in some studies, most of the patients with performed appendicitis were over the age of 50 $[1,9,14,18]$. This finding can be explained in two ways. The first possibility is the presence of two different appendicitis types as with and without perforation threshold and appendicitis with perforation might be more frequent among the elderly. The second possibility is the incidence of appendicitis decreases with increasing age but there are some factors, which might cause the elderly patients not to admit to hospital earlier, compared to the younger ones. According to our data, all appendicitis cases did not result with perforation, because there were phlegmonous appendicitis cases albeit the presences of long term pain. It is possible that the progression of appendicitis inflammation depends on multiple factors. The anatomical and physiological changes of appendix were claimed as a reason of rapid disease progression at older ages [10]. There are several reports, which present high perforation incidence rates in males, comparing with females $[1,18]$. A similar tendency was present in our study but, it did not reach a statistical significant level. Considering the 
diagnostic difficulties in females, it is pretty remarkable that the tendency of perforation in males is higher than females.

As a result, the delay of admission is the main predictive factor for appendicitis complications. Development of appendix perforation is not affected by age or gender. The rate of negative laparotomy is higher in females, who are in the reproductive period. Ultrasonography is successful in determining the perforation. However, it is not superior than the clinical examination for diagnosis.

\section{References}

1. Hale DA, Molloy M, Pearl RH, Schutt DC, Jaques DP. Appendectomy: a contemporary appraisal. Ann Surg. 1997;225(3):252-261.

2. Von Titte SN, McCabe CJ, Ottinger LW. Delayed appendectomy for appendicitis: causes and consequences. Am J Emerg Med. 1996;14(7):620-622.

3. Temple CL, Huchcroft SA, Temple WJ. The natural history of appendicitis in adults. A prospective study. Ann Surg. 1995;221(3):278-281.

4. Pittman-Waller VA, Myers JG, Stewart RM, Dent DL, Page CP, Gray GA, Pruitt BA, Jr., et al. Appendicitis: why so complicated? Analysis of 5755 consecutive appendectomies. Am Surg. 2000;66(6):548-554.

5. Maroju NK, Robinson Smile S, Sistla SC, Narasimhan R, Sahai A. Delay in surgery for acute appendicitis. ANZ J Surg. 2004;74(9):773-776.

6. Korner H, Sondenaa K, Soreide JA. Perforated and nonperforated acute appendicitis--one disease or two entities? Eur J Surg. 2001;167(7):525-530.

7. Luckmann R. Incidence and case fatality rates for acute appendicitis in California. A population-based study of the effects of age. Am J Epidemiol. 1989;129(5):905-918.

8. Andersson R, Hugander A, Thulin A, Nystrom PO, Olaison $\mathrm{G}$. Indications for operation in suspected appendicitis and incidence of perforation. BMJ. 1994;308(6921):107-
110 .

9. Korner H, Sondenaa K, Soreide JA, Andersen E, Nysted A, Lende TH, Kjellevold KH. Incidence of acute nonperforated and perforated appendicitis: age-specific and sex-specific analysis. World J Surg. 1997;21(3):313317.

10. Paajanen H, Kettunen J, Kostiainen S. Emergency appendectomies in patients over 80 years. Am Surg. 1994;60(12):950-953.

11. Velanovich V, Satava R. Balancing the normal appendectomy rate with the perforated appendicitis rate: implications for quality assurance. Am Surg. 1992;58(4):264269.

12. Calder JD, Gajraj H. Recent advances in the diagnosis and treatment of acute appendicitis. Br J Hosp Med. 1995;54(4):129-133.

13. Eldar S, Nash E, Sabo E, Matter I, Kunin J, Mogilner JG, Abrahamson J. Delay of surgery in acute appendicitis. Am J Surg. 1997;173(3):194-198.

14. Hansson LE, Laurell H, Gunnarsson U. Impact of time in the development of acute appendicitis. Dig Surg. 2008;25(5):394-399.

15. Rao PM, Rhea JT, Novelline RA, Mostafavi AA, McCabe CJ. Effect of computed tomography of the appendix on treatment of patients and use of hospital resources. N Engl J Med. 1998;338(3):141-146.

16. Poortman P, Lohle PN, Schoemaker CM, Oostvogel HJ, Teepen HJ, Zwinderman KA, Hamming JF. Comparison of CT and sonography in the diagnosis of acute appendicitis: a blinded prospective study. AJR Am J Roentgenol. 2003;181(5):1355-1359.

17. Hong JJ, Cohn SM, Ekeh AP, Newman M, Salama M, Leblang SD. A prospective randomized study of clinical assessment versus computed tomography for the diagnosis of acute appendicitis. Surg Infect (Larchmt). 2003;4(3):231-239.

18. Moss JG, Barrie JL, Gunn AA. Delay in surgery for acute appendicitis. J R Coll Surg Edinb. 1985;30(5):290-293. 